\title{
Modern considerations on the predisposing factors in the etiopathogenesis of systemic lupus erythematosus
}

\author{
Ionica-Mariana Radulescu ${ }^{1,2}$, Mihail Alecu' ${ }^{1}$, Laura Ion ${ }^{1,2}$, Cosmin Moldovan ${ }^{1,2}$ \\ ${ }^{1}$ Faculty of Medicine, "Titu Maiorescu" University, Bucharest, Romania \\ 2"Titu Maiorescu" Policlinic, Regina Maria Private Health Network, Bucharest, Romania
}

\begin{abstract}
Lupus erythematosus is an autoimmune disease with severe skin involvement and/or multisystemic implications characterized by the development of autoantibodies and immune complexes that, in turn, cause inflammation, tissue damage and a variety of clinical manifestations. The etiopathogeny of lupus erythematosus is very complex and still incompletely discovered. The onset of this disease or the episodes of exacerbation involves various factors: genetic, immune, hormonal, environmental but many more are still under research. There is strong evidence to back up the theory of an autoimmune disease, even though the precise mechanism is yet to be discovered. Apart from a preexisting background predisposing to lupus, certain triggers are required to act in a synergic way to determine the onset of the clinical signs. Studies show that it is 10-15 times more common in women of childbearing age than men, with a higher incidence amongst Afro-American population compared to Caucasians. The aim of this article is to shed some light on the most important determining and trigger factors involved in systemic lupus erythematosus by reviewing the most recent published data.
\end{abstract}

Keywords: lupus erythematosus, etiology, predisposing factors

\section{INTRODUCTION}

The identification and characterization of genetic risk factors for lupus will lead to improved diagnosis and therapeutic management for this complex disease (1-6). All the research available up until today underline that genes are associated with the clearance of immune complexes, genetic markers are associated with immune abnormalities in systemic lupus erythematosus (SLE) and also genes are associated with apoptosis in SLE. But genetic component is not the only risk factor involved. In the following we will try to synthetize all the major factors and their impact in the development of this disease.

\section{MODERN CONSIDERATIONS ON PREDISPOSING FACTORS}

\section{Genetic factors}

The importance of genetic factors has been studied for quite some time. There is strong evi- dence that genes play an important role in the etiopathogenesis of lupus. Studies focused on families with lupus show that the risk between heterozygous twins is $5 \%$ but can be as high as $25 \%$ for homozygous ones. In addition, Systemic lupus erythematosus (SLE) patients have at least one family member with some form of lupus disease. Therefore, it is safe to assume that relatives who develop SLE more commonly are the monozygotic twins who have a certain sequence of the genetic code identical. The incidence is lower in dizygotic twins, relatives of the first and second-degree. Cases of monozygotic twins in which only one was affected by SLE are distinguished by the fact that the unaffected subject has a different cellular response, and the number and activity of T-helper lymphocytes and T-suppressor are normal.

After some studies SLE is a family disease, heredity manifesting in $66 \%$ of cases of SLE (7-9), but the gene or genes that encode this disease and the nature of anomalies affecting them remain still largely unknown (7). 
Murine experimental models have shown that the genetic modification of a single molecule involved in the removal of apoptotic bodies, of the complement cascade or the activation or lymphocyte viability, can induce lupus. In humans, the major genetic contribution at the development of SLE is probably for patients with a genetic deficiency of one the complement cascade factors (C1q, C2, C4). One Japanese study reported two heterozygous carrier patients of the DNase 1 gene mutation. The study also identified a family of patients with elevated serum levels of IFN-alpha, the underlying cause being probably the duplication of IFN-alpha locus. These monogenic cases are exceptional, and anomalies are more often polygenic. Currently, the best researched genes are the ones on the receptors for the Fc portion of $\mathrm{IgG}$, the genes of the molecules from the major histocompatibility complex and of the components of the complement cascade and the genes that encode the protein production that play a major role in the immune system. An increased risk of SLE was associated with the existence of a particular functional polymorphism in the $\mathrm{C}$-reactive protein gene locus and the locus of the programmed cell death gene protein 1 (PDCD-1).

Two extensive studies independently showed that haplotype 5 particular interferon regulatory factor (IRF-5), the molecule that controls the secretion of numerous pro-inflammatory cytokines, has a significant risk factor in the development of SLE (10-13).

Results of several other studies have shown that the presence of LRI Yaa gene makes the body more susceptible to developing SLE. The newly discovered action mechanism relays on the disturbance in immune function on mice: receptor gene, Ly108 contributes to the loss of control on B lymphocytes, which in turn causes the production of autoantibodies responsible for clinical manifestations of SLE $(14,15)$.

Only $3-18 \%$ of patients with SLE have close relatives who have already expressed their disease and only $5 \%$ of children of parents with SLE will have the condition. Although related persons that develop SLE might present different clinical manifestations with variable intensity in clinical manifestations of various organs and systems, they carry the same types of autoantibodies, thus underling the obvious role of the genetic code.

People who will develop SLE show a higher incidence of anti-RNA antibodies, anti-DNA antibodies, anticardiolipin, and an increased function of the T-suppressor lymphocytes (16). Studies con- ducted so far suggest many different genes that contributes to susceptibility to lupus and that no single genetic abnormality is responsible for the onset of the disease. Also, it seems that genes may also play a major role in determining the type or SLE severity.

Genes that have been associated with the LE in humans include:

- the genes for renal receptors with a low efficiency in capturing the immune complexes present in the Afro-American patients with lupus nephritis in a higher proportion than in those with other clinical manifestations.

- immune system genes like HLA-DR3, B8, DR2, A1, C4A, Drw3, Drw12 (17-21) which have an increased frequency among Caucasian patients with SLE

- alleles of HLA-DR2 and HLA-DQ, which are associated with certain autoimmune features found in the SLE

- in black patients there is also an association of the immune system genes with Ig allotype Gm 1:17.

- genetic complement factors deficiency, in particular $\mathrm{C} 4$ and $\mathrm{C} 2$, but other components may be affected as well, is common in familial cases of SLE (18).

- a T cell receptor polymorphism, which has been associated with anti-Ro antibodies, one of autoantibodies commonly found in mothers whose children develop neonatal LE.

Animal studies have recently discovered a single gene that causes in mice a disease very similar with lupus. In mice, gene Fas is the deficient one; it controls and regulates apoptosis. When this gene is replaced with a normal one, mice will no longer develop signs and symptoms of SLE.

A study conducted by the Oklahoma Medical Research Foundation (OMRF) researchers, representing the culmination of an extensive international collaboration, identified three new genes with statistical significance in assessing the risk of lupus. The highlight of the study was the inclusion of several ethnic groups and the results show that genes that cause lupus are not always the same, IRF8 and TMEM39a are associated with lupus at Caucasian, Afro-American, and Asians patients. A third gene, called IKZF3, was present only in samples from Caucasians and Afro-Americans.

\section{Hormonal factors}

SLE is attributed mostly to young women and especially women at childbearing age (the disease rarely begins before puberty or after menopause), 
with common exacerbations during pregnancy or postpartum and premenstrual or menstrual periods.

The estrogen is involved which stimulates the immune response and the testosterone has inhibitory effects on the immune response, but rest of the exact mechanism is not known. Women with SLE had lower levels of androgens and some males affected by SLE can also have abnormal levels of androgens.

A decrease in testosterone levels by the increase of the oxidation on C-17 level under the action of 17beta-hydroxy-steroid dehydrogenase generating androstenedione was found in women with active SLE. It was therefore assumed that the oxidation of testosterone (biologically active androgen) should be involved in the production of SLE. A decrease of hydroxylation at C-2 level of the estrogen causing low blood levels of 2-hydroxy-estrone, 2-methoxy-esronei that are catechol estrogens with low or no activity was also discovered in women with SLE (16). Hydroxylation of estrogen at the C-6 level is elevated in SLE both in women and in men, increasing concentrations in blood levels of 16 alpha-hydroxy-estrone and estriol (16). Estrogens stimulate the immune system, and testosterone have inhibitory effects on its. Estrogen administration in women with SLE will induce disease exacerbation (16).

Cytokines, major immune factors of histocompatibility who are active in SLE are directly affected by sex hormones, generally estrogen and testosterone that increase antibody production, although their exact role in SLE is more complex because there are different ways in which each hormone can affect different immune cells.

Prolactin may play a role in the etiology of SLE by stimulating the immune response. Serum hyperprolactinemia could, however, be the result of poor response of the pituitary-adrenal-hypothalamic axis to cytokines (22).

Some studies show that women taking oral contraceptives or had replacement therapy with estrogen, have an increased risk of developing SLE, perhaps because the estrogen binds to white blood cells, which play a major part of the immune response and increase the lifetime of the cells. Whatever causes a prolonged immune response may trigger lupus. However, there is a disagreement among researchers whether the use of birth control pills or hormone replacement in postmenopausal phase increase the risk for lupus.

In animals, a lupus-like disease is exacerbated when receiving estrogen. Studies are underway to learn more about how hormones may influence the evolution and development of SLE.

\section{Ultraviolet radiation}

Ultraviolet (UV) radiation can be a possible trigger and aggravating factor in SLE.

Exposure to UV-B radiation causes the accumulation of abnormally high protein on the cell surface. These proteins react with autoantibodies of the patients with SLE, causing a local or systemic inflammatory response.

It seems that the etiopatogenic involvement of UV radiation in discoid lupus erythematosus (DLE) may have a more important role than in LES, causing DNA damage, with anti-DNA antibody formation and the formation of immune complexes, complement activation and the appearance of an inflammatory response. Also, there is an increase in release of IL-1 by the keratinocytes and Langerhans cells, and a decrease in suppressor $\mathrm{T}$ cell activity.

The UV radiation spectrum involved corresponds to the UV-B (290-320 nm) and UV-A (320$400 \mathrm{~nm}$ ) wavelength ranges. According to some authors, the UV-C radiation band (200-290nm) may also be involved. The chromophore responsible for the photosensitivity to UV-B and UV-C is the DNA. The UV distorts the DNA and subsequently this will lead to an increase production of antibodies. The UV irradiation-induced production of antibodies is dependent on the cellular cytotoxicity, that and that reaction appears to be responsible for the degeneration of basal cell.

UV irradiated keratinocytes cultures produce anti-Ro antibodies which can be found in the serum of patients with SLE with increased photosensitivity. However, there is no correlation between the serum levels of these antibodies and the disease's activity.

The keratinocytes of the patients who were exposed to UV radiation have a greater affinity for autoantibodies compared to UV-protected keratinocytes (23). This statement could be related with the location of the skin lesions in SLE on sun-exposed areas.

Other studies suggest that visible light could play a role in the pathogenesis of skin lesions in LE, and also heat could act as a possible trigger and aggravating factor for SLE. Exposure to sunlight or UV radiation can easily precipitate or exacerbate SLE activity in over $60 \%$ cases (24).

\section{Viral infections}

Many researchers, investigating the role of infectious etiologies, promote the theory that infec- 
tious agents such as viruses can trigger SLE by disrupting immune cell function in susceptible patients. It is possible that certain viruses infect B cells (which are designed to induce antibody response to specific antigens) and forces them to produce antibodies.

The complex relationship between the genetic factors, possible viral infection and low cell-mediated immunity suggest that the genetic factors may allow viral replication in the thymus therefore altering the production and maturation of $\mathrm{T}$ lymphocytes and thus resulting in decrease cellular immunity.

The incidence and high levels of anti-dsRNA reovirus antibodies (70\% cases), anti-rubella, antimeasles, anti-parainfluenza or anti-Epstein-Barr virus that have been found in SLE, strongly suggests the role of viruses in causing this disease but could also be the result of a decreased $\mathrm{T}$ lymphocytes activity.

According to some studies (25) it is possible that the etiology of SLE may also involve viral and type C immune complex, human parvovirus B19 (26) or Epstein-Barr virus (27). It has been suggested that there is a strong association between the Epstein-Barr virus (EBV) infection and the increased risk of lupus, especially Afro-American population. This virus is responsible for the emergence of mononucleosis and up tp the age of 40 the chances of infection are extremely high, of about $95 \%$. Because leukocyte-binding viruses can remain stuck inside them for several years, many researchers believe it can stimulate an autoimmune response at certain people.

Another study showed that, although $95 \%$ of the people are infected with EBV, less than $2 \%$ develop an autoimmune disease that is correlated directly with the virus. This suggests that infection with EBV does not necessarily lead to the development of an autoimmune disease.

Studies on an animal model, particular with mice, have used gamma-herpesvirus 68 (MHV-68), which is similar to EBV and has the potential to infect mice, unlike EBV which doesn't. It was examined whether the infection with gammaherpes-68 virus is causing autoimmunity in healthy mice and the ones predisposed to lupus. The study focused on the effects of the infection upon the autoimmune process associated with $\mathrm{B}$ and $\mathrm{T}$ lymphocytes and renal pathology associated with the disease. Test results showed that mice produce autoantibodies after their acute infection, but this antibody production simply reflects an increased total antibody count, as a response to the acute infection. This increase is especially determined by the non-specific stimulation of lymphocytes B. Measuring the levels of the autoantibodies in the non-immune mice the study determined that these autoantibodies were produced only 8 weeks after infection and then serum count was no longer present. This suggests that antibodies are produced only by viral infection. The healthy mice infected with MHV-68, were studied for a year and had a normal or even low lymphocytes count and a normal renal function; therefore, these mice did not develop an autoimmune disease. The relationship between EBV human infection and autoimmunity that was developed only in selected cases shows us that EBV could produce autoimmunity only in individuals genetically predisposed to develop the disease.

Other experiments determined that infection with MHV-68 does not trigger or exacerbate the disease in healthy mice but on the contrary, it inhibits the development and progression of SLE at organ and cellular level.

Warts occur frequently in patients with SLE, particularly in the elderly, although the incidence of anti-antibodies human papilloma virus is low (probably poor immune mechanism) and there is an inverse relationship between the appearance of warts and presence of FR.

\section{Autoantibodies}

One of the most distinct signs of lupus is the formation of antibodies directed against its own tissues.

Amongst the humoral non-specific autoantibodies occurring in SLE some are being more specific (anti-dsDNA and anti-Sm) others just being found in SLE with an increased frequency (ANA and anti-Ro). The disease can be produced by the development of these antibodies or the activation of the polyclonal B-lymphocytes and the production of specific antibodies. Most autoantibodies found in SLE are directed to intracellular nucleoprotein particles, $98 \%$ of patients have antinuclear antibodies, while the anti-double stranded DNA antibodies are present in only $50-80 \%$ of patients

However, antibodies are not specific to any disease, are not present in all cases of SLE, their levels are independent of the activity of the disease in the majority of cases, they cross the placental barrier without replicating the disease in all fetuses and can be transfused without inducing a clinical manifestation.

ANA and anti-DNA can cause antigen-antibody reactions, and also gamma-IFN release from 
monocytes, resulting in strong immunological and inflammatory reactions. Anti-Ro antibodies are involved in the production of erythema and heart block in neonatal SLE cases and APL (including lupus anticoagulant) generates thrombosis and abortions.

There were reported cases of neurofibrils antibodies (21\% LES) but with no correlation with some sort of neurological involvement.

Recent studies have demonstrated that the development of autoantibodies takes places years before the onset of clinical manifestations of SLE and the antiphospholipid syndrome. Researchers also described the prevalence of autoantibodies, such as antinuclear antibodies, anti-Ro, anti-La, anti-Sm, anti-RNP and antiphospholipid (APL), before the development of clinical manifestations of SLE. Antinuclear antibodies occur earlier than anti-DNA antibodies, and a significant number of patients have an increased anti-DNA antibodies serum levels even before the diagnosis, suggesting a gradual increase of the autoimmunity. These data also suggest that the presence of just autoantibodies does not necessarily lead to a clinical-manifest disease and possibly other factors, such as genetic and environmental, must be concurrently involved in order to trigger a full disease manifestation. Therefore, it was suggested that it may be possible to predict the onset of clinical manifestations of SLE through clinical evaluation and monitoring the development of various autoantibodies of SLE.

The potential pathogenesis of anti-DNA antibodies remains controversial. Several animal models and experiments suggest that these autoantibodies can cause kidney damage in mice with severe combined immunodeficiency (SCID). However, the evidence is less convincing in people (28-31).

\section{Immune system disorders}

Many immunological abnormalities that occur in patients with SLE have been identified, but it is still unknown which mechanism is the primary and the secondary one.

Immune system activation in systemic lupus shows several pathological characters. It is chronic, self-reactive and generates tissue damage. There are complex interactions between overactive $\mathrm{B}$ cells, T lymphocytes and antigen-presenting cells (mostly dendritic cells). The presence of antinuclear antibodies represents the immunological abnormality that can be found in nearly all patients with lupus. They are directed against chromatin and its constituents, such as anti-DNA native anti- body (anti-ADNn) mono-carenar anti-DNA antibody (anti-ADNsb), anti-RNA antibodies and anti-histone antibody. They also are directed against soluble nuclear antigens: anti-Sm, U1-RNP antibodies, anti-ribosomal, anti-SSA and anti-SSB.

Autoantibodies in patients with SLE are often referred to as ANA because they target nucleic acids and nuclear proteins (23). Antinuclear autoantibodies, typically met in SLE, recognize native DNA with high affinity.

There are also less commonly encountered antibodies, directed against molecules from the surface of hematopoietic cells, antibodies that are associated with vascular thrombosis: antiphospholipid and anti-beta-2 glycoprotein-1.

Among autoantibodies found in lupus patients some might be particular involved in the production of tissue damage by forming immune complexes. In tissues, immune complexes (molecular complexes formed from one antibody binned to the autoantigens) activates the classical complement pathway, which initiate in turn an inflammatory reaction, mobilizing the in-situ macrophages, the polynuclear neutrophils, the dendritic cells and lymphocytes, leading ultimately to the destruction of the cell.

It seems that antibodies are not the only immunological factors that can generate damaged tissue. Therefore, skin or kidney infiltration by T lymphocytes, particularly CD8 ones allows us to suspect their direct involvement in tissue lesions. In addition, certain cytokines such as interferon-alpha (IFN-alpha), interferon-gamma (IFN-gamma) and alph tumor necrosis factor (TNF-alpha) could directly induce tissue lesions. Therefore, the lymphocyte T/B balance is changed, causing exaggerated response of circulating antibodies and low cellular immune response, probably due to the drop of suppressor/inductor T lymphocytes. Both the number and the activity of $\mathrm{T}$ lymphocytes are low and as such Il-2 production is reduced, resulting in a decrease of activated B-cells inhibitor activity $(27,32)$.

Many studies concurred that the NK cells have increased activity in SLE. Complement activation occurs, and $\mathrm{C} 3 \mathrm{a}$ and $\mathrm{C} 5 \mathrm{a}$ anaphylatoxins increase during exacerbation of the disease, contributing most likely in the pathogenesis of the vascular lesions.

\section{Bacterial infections}

Bacterial infections can precipitate SLE. Decreased serum levels of antibodies generate chemotactic factors that may contribute to the increased 
incidence of infections. Initially the neutrophils and macrophages-driven phagocytosis is low. A possible retrofitting of LES is possible in some of these patients.

\section{Stress}

Stress may also be considered a possible trigger-factor for SLE patients, often attributed to a stressful event that will generate as a first symptom of the disease or worsening of general condition. It turns out that stress can cause an increase in cellular and humoral immune response, but there is no clear explanation of these phenomena. Some ongoing extensive research is focused on how stress hormones such as adrenaline and cortisone can influence the clinical course of SLE.

\section{Smoking and alcohol consumption}

Smoking may be a risk factor for the onset of SLE and increase the risk of skin and kidney damage, especially in women with lupus. Some epidemiological studies have suggested that smoking is a risk factor for EL, probably for genetically predisposed patients. Still, if smoking increases the risk of development it remains controversial.

Several studies have focused on SLE patients, including women with 4 or more criteria on ACR scale. The studies of Penha et al. and Miot et al. $(33,34)$ explored discoid lupus erythematosus (DLE) in smokers with less than 4 ACR criteria and noticed an increase in prevalence of smoking (84.2\%) compared to the patients in the control group $(33.5 \%)$. A close connection between LE and tobacco was also observed in Gallego's study (35).

However, the mechanism of how smoking can cause LE remains unclear, but lately several assumptions were made. Cigarette smoke contains more than 100 toxic and carcinogens substances. Some of them are qamine-aromatic, also found in drugs, which are known to be responsible for the appearance LE, especially DLE. The research conducted by Costenbader and Karlson demonstrated that, from immunologically point of view, smoking has complex modulators effects. Other indirect evidence to support that is that antimalarials drugs are known to have less effect on smokers. Although the effect is not fully understood, antimalarials may be P450 inactivated. Polycyclic aromatic hydrocarbons found in cigarette smoke, are potential inducers of P450 enzyme complex. Smoking might not be a risk factor for itself, but susceptibility to LE and dependence on cigarettes may have a genetic background, as discussed Boeckler and Fust, as a group of genes for olfactory receptors involved in smoking habits and addictions is located near the HLA class 1 , where some alleles are located and are known risk factors for SLE.

However, data from studies regarding alcohol and LE is conflicting. Some studies have shown a protective effect, while others have not shown a clear association. In medical practice clinicians observed that men and women with severe disseminated DLE and those with less than 4 ACR criteria were frequently alcoholics (36-38).

Based on all literature available up to now, we can definitely state that smoking and alcohol consumption can be a risk factor (39-47).

\section{Vitamin $\mathrm{D}$ deficiency}

A study suggests that low vitamin D serum levels increases the production of autoantibodies at healthy people. Vitamin D deficiency has also been linked to hyperactivity of B cells and activation of the IFN-alpha in patients with SLE (48-50). An Indonesian study showed that the average level of vitamin D in patients with SLE was below normal, and significantly lower compared to the healthy witness. Also, Kim et al. came to the same conclusion $(51,52)$. The vitamin D concentration found in patients with SLE is not surprising since patients with SLE often have a higher risk factor for low levels of vitamin D, such as the use of sunscreen in the long term, the lack of food intake, and the use of clothes that cover the whole body. SLE patients tend to avoid the sun because photosensitive skin eruptions and the potential for disease flare. It is also known that patients with SLE produce anti-vitamin D antibodies.

Vitamin D deficiency in patients with lupus was associated with greater fatigue and vascular stiffness. A study shows that vitamin D had lower levels in patients with kidney disorders in SLE than in those without renal manifestations (53-61).

Although many experts recommend vitamin D supplementation to correct vitamin D deficiency in patients with SLE, the effect of the supplement has not been established.

\section{Chemical factors}

There are many cases of SLE in populations with high exposure to certain chemicals. Some environmental factors could induce the appearance of SLE, such as cooking denatured oil by heating, heavy metals, silicates (crystalline silicon), trichlorethylene, silicone breast implant, hydrazine (plastic, rubber, chlorinated pesticides, herbicides, textile, paint and corrosion) and aromatic amines found in the painting and hair dye (62-64). 


\section{Drugs or drug-induced lupus erythematosus}

Several drugs can induce lupus in susceptible individuals. Drugs with proven connection with SLE $(65,66)$ are: chlorpromazine, hydralazine, isoniazid, methyldopa, procainamide. When the intake of the above-mentioned drugs ceases, the symptoms disappear. The overall incidence of drug induced SLE is estimated between 3 and $12 \%$ of cases.

Oral contraceptives and hormone replacement therapy administered in premature menopause may activate SLE through the presence of estrogen. Women diagnosed with lupus should avoid using them due to an increased risk of thrombosis and heart damage.

SLE induced by medication commonly occurs in the elderly. The clinical manifestation of this syndrome is pleural and pericardial inflammation, fever, rash and arthritis. Serological modifications may also occur. Central nervous system and renal impairment is rare in this type of SLE, antihistone antibodies occur frequently, but instead, anti-DNA antibodies are absent, and the serum complement is normal. The skin manifestation might consist of blisters, bubbles, erythema and gangrene pyoderma (67-69).

By Cush (70), the diagnostic criteria for drug induced SLE are:

- no priors suggestive for SLE, before drug ingestion

- ANA production and at least one manifestation of lupus during treatment

- rapid decline in clinical manifestation and the gradual disappearance of autoantibodies after stopping the administration of the drug.
This type of SLE is associated with an increased incidence of HLA-DR4 and occurs more often in women than in men (4:1) suggesting also a probable a genetic predisposition (71).

The patients with slow glycosylation treated with isoniazid or procainamide develop more often SLE, than those with fast acetylation. Hydralazine, isoniazid and penicillamine inhibits the reaction of covalent binding of $\mathrm{C} 4$ through competitive binding to the active situs and thus interferes with his protecting function (18).

\section{CONCLUSIONS}

All research indicates that LE is an autoimmune disease with multisystemic implications based on the development of autoantibodies and immune complexes that may trigger severe tissue damage and, therefore, a variety of clinical manifestations.

The onset of this disease involves a large array of factors such as genetic, immune, hormonal, environmental, with many still under research. The evidence that backs up the theory of an autoimmune disease is very compelling, even though the precise mechanism has yet to be completely discovered.

The precise identification and characterization of each contributing factor of lupus will lead to an improved diagnosis and overall therapeutic management of these cases but further research is still needed as this proves to be a complex disease with many intricating layers.

\section{REFERENCES}

1. Falasinnu T, O'Shaughnessy MM, Troxell ML, Charu V, Weisman $\mathrm{MH}$, Simard JF. A review of non-immune mediated kidney disease in systemic lupus erythematosus: A hypothetical model of putative risk factors. Semin Arthritis Rheum. 2020;50(3):463-72.

2. Gu C, Zhao R, Zhang X, Gu Z, Zhou W, Wang Y, et al. A metaanalysis of secondary osteoporosis in systemic lupus erythematosus: prevalence and risk factors. Arch Osteoporos. 2019;15(1):1.

3. Zamora LD, Collante MTM, Navarra SV. Risk factors for herpes zoster infection among Filipinos with systemic lupus erythematosus. Int J Rheum Dis. 2020;23(2):197-202.

4. Fernandez-Garces M, Haro G, Mico ML. Predisposing factors to nonfatal cardiovascular events in women with systemic lupus erythematosus. An observational, cross-sectional, multicenter study in Spain from the risk/systemic lupus erythematosus thematic network. Medicine. 2019;98(43):e17489.

5. Rianthavorn P, Prurapark P. Risk factors of infection-associated mortality in children with lupus nephritis in under-resourced areas. Lupus. 2019;28(14):1727-34.

6. Yuan F, Wei F, Wang J, You Y. Clinical aspects and risk factors of lupus nephritis: a retrospective study of 156 adult patients. The Journal of International Medical Research. 2019;47(10):5070-81.

7. Hay EM, Snaith ML. ABC of rheumatology. Systemic lupus erythematosus and lupus-like syndromes. BMJ. 1995; 310(6989):1257-61.

8. Jimenez S, Cervera R, Font J, Ingelmo M. The epidemiology of systemic lupus erythematosus. Clin Rev Allergy Immunol. 2003;25(1):3-12.

9. Lawrence JS, Martins CL, Drake GL. A family survey of lupus erythematosus. 1. Heritability. J Rheumatol. 1987;14(5):913-21.

10. Idborg H, Zandian A, Ossipova E, Wigren E, Preger C, Mobarrez F, et al. Circulating Levels of Interferon Regulatory Factor-5 Associates With Subgroups of Systemic Lupus Erythematosus Patients. Front Immunol. 2019;10:1029.

11. Bae SC, Lee YH. Association between the interferon regulatory factor 5 rs2004640 functional polymorphism and systemic lupus erythematosus: an updated meta-analysis. Lupus. 2019;28(6):740-7.

12. Calise J, Marquez Renteria S, Gregersen PK, Diamond B. LineageSpecific Functionality of an Interferon Regulatory Factor 5 Lupus Risk Haplotype: Lack of B Cell Intrinsic Effects. Front Immunol. 2018; 9:996.

13. Liu J, Berthier CC, Kahlenberg JM. Enhanced Inflammasome Activity in Systemic Lupus Erythematosus Is Mediated via Type I Interferon- 
Induced Up-Regulation of Interferon Regulatory Factor 1. Arthritis Rheumatol. 2017;69(9):1840-9.

14. Ahmed S, Ihara K, Kanemitsu S, Nakashima H, Otsuka T, Tsuzaka $\mathrm{K}$, et al. Association of CTLA-4 but not CD28 gene polymorphisms with systemic lupus erythematosus in the Japanese population. Rheumatology (Oxford). 2001;40(6):662-7.

15. Alarcon GS, McGwin G, Jr., Bastian HM, Roseman J, Lisse J, Fessler BJ, et al. Systemic lupus erythematosus in three ethnic groups. VII [correction of VIII]. Predictors of early mortality in the LUMINA cohort. LUMINA Study Group. Arthritis Rheum. 2001;45(2):191-202.

16. Alarcon-Segovia $D$. The pathogenesis of immune dysregulation in systemic lupus erythematosus. A troika. J Rheumatol. 1984;11(5):588-90.

17. Alarcon-Segovia D, Drenkard C, Villa AR. Survival of Mexican patients with systemic lupus erythematosus. Rheumatology (Oxford). 2001;40(2):228-9.

18. Johansson-Stephansson E, Koskimies S, Partanen J, Kariniemi AL. Subacute cutaneous lupus erythematosus. Genetic markers and clinical and immunological findings in patients. Arch Dermatol. 1989;125(6):791-6.

19. Harley JB, Sheldon P, Neas B, Murphy S, Wallace DJ, Scofield RH, et al. Systemic lupus erythematosus: considerations for a genetic approach. J Invest Dermatol. 1994;103(5 Suppl):144S-9S.

20. Alarcon-Riquelme ME. Family studies in systemic lupus erythematosus. Rheumatology (Oxford). 2002;41(4):364-6.

21. Georgescu L, Vakkalanka RK, Elkon KB, Crow MK. Interleukin-10 promotes activation-induced cell death of SLE lymphocytes mediated by Fas ligand. The Journal of Clinical Investigation. 1997; 100(10):2622-33.

22. Gutierrez MA, Garcia ME, Rodriguez JA, Rivero S, Jacobelli S. Hypothalamic-pituitary-adrenal axis function and prolactin secretion in systemic lupus erythematosus. Lupus. 1998;7(6):404-8.

23. Zamansky GB. Sunlight-induced pathogenesis in systemic lupus erythematosus. J Invest Dermatol. 1985;85(3):179-80.

24. Katayama S, Panelius J, Koskenmies S, Skoog T, Mahonen K, Kisand K, et al. Delineating the Healthy Human Skin UV Response and Early Induction of Interferon Pathway in Cutaneous Lupus Erythematosus. J Invest Dermatol. 2019;139(9):2058-61 e4.

25. Roblot $P$, Roblot $F$, Ramassamy A, Becq-Giraudon B. Lupus syndrome after parvovirus B19 infection. Rev Rhum Engl Ed. 1997;64(12):849-51.

26. Larson JD, Thurman JM, Rubtsov AV, Claypool D, Marrack P, van Dyk LF, et al. Murine gammaherpesvirus 68 infection protects lupus-prone mice from the development of autoimmunity. Proceedings of the National Academy of Sciences of the United States of America. 2012;109(18):E1092-100.

27. Goldman M. Cytokines in the pathophysiology of systemic lupus erythematosus. Autoimmunity. 1990;8(2):173-9.

28. Fujieda Y, Mader S, Jeganathan V, Arinuma Y, Shimizu Y, Kato M, et al. Clinical significance of anti-DNA/N-methyl-D-aspartate receptor 2 antibodies in de novo and post-steroid cases with neuropsychiatric systemic lupus erythematosus. Int J Rheum Dis. 2019;22(3):443-8.

29. Bragazzi NL, Watad A, Damiani G, Adawi M, Amital H, Shoenfeld Y. Role of anti-DNA auto-antibodies as biomarkers of response to treatment in systemic lupus erythematosus patients: hypes and hopes. Insights and implications from a comprehensive review of the literature. Expert Rev Mol Diagn. 2019;19(11):969-78.

30. Pisetsky DS, Rovin BH, Lipsky PE. New Perspectives in Rheumatology: Biomarkers as Entry Criteria for Clinical Trials of New Therapies for Systemic Lupus Erythematosus: The Example of Antinuclear Antibodies and Anti-DNA. Arthritis Rheumatol. 2017;69(3):487-93.

31. VanPatten S, Sun S, He M, Cheng KF, Altiti A, Papatheodorou A, et al. Amending HIV Drugs: A Novel Small-Molecule Approach To Target Lupus Anti-DNA Antibodies. Journal of Medicinal Chemistry. 2016;59(19):8859-67.

32. Tanaka A, Sugawara A, Sawai K, Kuwahara T. Human parvovirus B19 infection resembling systemic lupus erythematosus. Intern Med. 1998;37(8):708-10.
33. Penha MA, Liborio RDS, Miot HA. Rituximab in the treatment of extensive and refractory subacute cutaneous lupus erythematosus. An Bras Dermatol. 2018;93(3):467-9.

34. Miot HA, Bartoli Miot LD, Haddad GR. Association between discoid lupus erythematosus and cigarette smoking. Dermatology. 2005;211(2):118-22.

35. Gallego H, Crutchfield CE, 3rd, Lewis EJ, Gallego HJ. Report of an association between discoid lupus erythematosus and smoking. Cutis. 1999;63(4):231-4.

36. Wang J, Liu J, Pan L, Guo L, Liu C, Yang S. Association between alcohol intake and the risk of systemic lupus erythematosus: A systematic review and meta-analysis. Lupus. 2021:961203321991918.

37. Hahn J, Leatherwood C, Malspeis S, Liu X, Lu B, Roberts AL, et al. Associations between daily alcohol consumption and systemic lupus erythematosus-related cytokines and chemokines among US female nurses without SLE. Lupus. 2020;29(8):976-82.

38. Bae SC, Lee YH. Alcohol intake and risk of systemic lupus erythematosus: a Mendelian randomization study. Lupus. 2019;28(2):174-80.

39. Cozier YC, Barbhaiya M, Castro-Webb N, Conte C, Tedeschi SK, Leatherwood C, et al. Relationship of Cigarette Smoking and Alcohol Consumption to Incidence of Systemic Lupus Erythematosus in a Prospective Cohort Study of Black Women. Arthritis Care Res (Hoboken). 2019;71(5):671-7.

40. Kim SK, Lee SS, Choe JY, Park SH, Lee H. Effect of alcohol consumption and smoking on disease damage in systemic lupus erythematosus: data from the Korean Lupus Network (KORNET) registry. Lupus. 2017;26(14):1540-9.

41. Barbhaiya M, Lu B, Sparks JA, Malspeis S, Chang SC, Karlson EW, et al. Influence of Alcohol Consumption on the Risk of Systemic Lupus Erythematosus Among Women in the Nurses' Health Study Cohorts. Arthritis Care Res (Hoboken). 2017;69(3):384-92.

42. van Weelden M, Queiroz LB, Lourenco DM, Kozu K, Lourenco B, Silva CA. Alcohol, smoking and illicit drug use in pediatric systemic lupus erythematosus patients. Rev Bras Reumatol Engl Ed. 2016;56(3):228-34.

43. Takvorian SU, Merola JF, Costenbader KH. Cigarette smoking, alcohol consumption and risk of systemic lupus erythematosus. Lupus. 2014;23(6):537-44.

44. Kiyohara C, Washio M, Horiuchi T, Asami T, Ide S, Atsumi T, et al. Cigarette smoking, alcohol consumption, and risk of systemic lupus erythematosus: a case-control study in a Japanese population. J Rheumatol. 2012;39(7):1363-70.

45. Schubert C, Fuchs D. The relationship between alcohol intake and cellular immune activity in systemic lupus erythematosus may change from inhibitory to stimulatory within 2 months of study: findings from an integrative single-case study. Clin Rheumatol. 2010;29(2):229-30.

46. Wang J, Kay AB, Fletcher J, Formica MK, McAlindon TE. Alcohol consumption is not protective for systemic lupus erythematosus. Annals of the Rheumatic Diseases. 2009;68(3):345-8.

47. Boeckler P, Cosnes A, Frances C, Hedelin G, Lipsker D. Association of cigarette smoking but not alcohol consumption with cutaneous lupus erythematosus. Arch Dermatol. 2009;145(9):1012-6.

48. Adel Y, Sadeq Y. Impact of IL-34, IFN-alpha and IFN-lambda1 on activity of systemic lupus erythematosus in Egyptian patients. Reumatologia. 2020;58(4):221-30.

49. Houssiau FA, Thanou A, Mazur M, Ramiterre E, Gomez Mora DA, Misterska-Skora M, et al. IFN-alpha kinoid in systemic lupus erythematosus: results from a phase Ilb, randomised, placebocontrolled study. Annals of the Rheumatic Diseases. 2020; 79(3):347-55.

50. Simpson SR, Rego SL, Harvey SE, Liu M, Hemphill WO, Venkatadri $\mathrm{R}$, et al. T Cells Produce IFN-alpha in the TREX1 D18N Model of Lupus-like Autoimmunity. Journal of Immunology. 2020; 204(2):348-59.

51. Jung JY, Koh BR, Bae CB, Kim HA, Suh CH. Carotid subclinical atherosclerosis is associated with disease activity but not vitamin $D$ in Korean systemic lupus erythematosus. Lupus. 2014;23(14):1517-22. 
52. Kim HA, Sung JM, Jeon JY, Yoon JM, Suh CH. Vitamin D may not be a good marker of disease activity in Korean patients with systemic lupus erythematosus. Rheumatology International. 2011; 31(9):1189-94.

53. Correa-Rodriguez M, Pocovi-Gerardino G, Callejas-Rubio JL, Rios-Fernandez R, Martin-Amada M, Cruz-Caparros MG, et al. Vitamin D Levels are Associated with Disease Activity and Damage Accrual in Systemic Lupus Erythematosus Patients. Biol Res Nurs. 2020:1099800420983596.

54. Huang Z, Liu L, Huang S, Li J, Feng S, Huang N, et al. Vitamin D $(1,25-(\mathrm{OH}) 2 \mathrm{D} 3)$ Improves Endothelial Progenitor Cells Function via Enhanced NO Secretion in Systemic Lupus Erythematosus. Cardiol Res Pract. 2020;2020:6802562.

55. Tabra SAA, Abdelnabi HH, Darwish NFM, El-Barbary AM, AbdelGhafar MT, Abu-Zaid MH. Juvenile lupus and serum vitamin D levels: A cross-sectional study. Lupus. 2020;29(13):1752-8.

56. Tsai TY, Lee TH, Wang HH, Yang TH, Chang IJ, Huang YC. Serum Homocysteine, Folate, and Vitamin B12 Levels in Patients with Systemic Lupus Erythematosus: A Meta-Analysis and MetaRegression. J Am Coll Nutr. 2020:1-11.

57. Cardona-Cardona AF, Ceron YCJA. Vitamin D in Colombian patients with systemic lupus erythematosus and its correlation with disease activity. Lupus. 2020;29(10):1297-304.

58. Huang $Y$, Zhang $H$, Zhang S, Sun J. [Vitamin D receptor and monocyte chemoattractant protein-1 expressions in peripheral blood mononuclear cells in patients with systemic lupus erythemaotsus]. Nan Fang Yi Ke Da Xue Xue Bao. 2020;40(1):99-103.

59. Guan SY, Pan F. Accurately assess vitamin D status in patients with systemic lupus erythematosus. Autoimmun Rev. 2020;19(5):102510.

60. Sapkota S, Baig S, Hess T, O'Connell AM, Menk J, Shyne M, et al. Vitamin $D$ and bisphosphonate therapy in systemic lupus erythematosus patients who receive glucocorticoids: are we offering the best care? Lupus. 2020;29(3):263-72.

61. Yamamoto EA, Nguyen JK, Liu J, Keller E, Campbell N, Zhang CJ, et al. Low Levels of Vitamin D Promote Memory B Cells in Lupus. Nutrients. 2020;12(2).

Conflict of interest: none declared Financial support: none declared
62. Parks CG, De Roos AJ. Pesticides, chemical and industrial exposures in relation to systemic lupus erythematosus. Lupus. 2014;23(6):527-36.

63. Takeda Y, Takeno M, Iwasaki M, Kobayashi H, Kirino Y, Ueda A, et al. Chemical induction of $\mathrm{HO}-1$ suppresses lupus nephritis by reducing local iNOS expression and synthesis of anti-dsDNA antibody. Clinical and Experimental Rheumatology. 2004;138(2):237-44.

64. Reidenberg MM, Drayer DE, Lorenzo B, Strom BL, West SL, Snyder ES, et al. Acetylation phenotypes and environmental chemical exposure of people with idiopathic systemic lupus erythematosus. Arthritis Rheum. 1993;36(7):971-3.

65. Gunnarsson I, Kanerud L, Pettersson E, Lundberg I, Lindblad S, Ringertz B. Predisposing factors in sulphasalazine-induced systemic lupus erythematosus. Br J Rheumatol. 1997;36(10):1089-94.

66. Khosla R, Butman AN, Hammer DF. Simvastatin-induced lupus erythematosus. Southern Medical Journal. 1998;91(9):873-4.

67. Leung J, Baker EA, Kim AHJ. Exploring intentional medication non-adherence in patients with systemic lupus erythematosus: the role of physician-patient interactions. Rheumatol Adv Pract. 2021;5(1):rkaa078.

68. Tan QEC, Gao X, Ang WHD, Lau Y. Medication adherence: a qualitative exploration of the experiences of adolescents with systemic lupus erythematosus. Clin Rheumatol. 2021.

69. Guo J, Ren Z, Li J, Li T, Liu S, Yu Z. The relationship between cancer and medication exposure in patients with systemic lupus erythematosus: a nested case-control study. Arthritis Res Ther. 2020;22(1):159.

70. Cush JJ. Unusual toxicities with TNF inhibition: heart failure and drug-induced lupus. Clinical and Experimental Rheumatology. 2004;22(5 Suppl 35):S141-7.

71. Deluca HF, Cantorna MT. Vitamin D: its role and uses in immunology. FASEB J. 2001 Dec;15(14):2579-85. 